\title{
Revision of Central American species of Euryomma Stein (Diptera, Fanniidae), with description of two new species and updates of distributional records
}

\author{
Diana Grisales ${ }^{1}$, M. Cecilia Domínguez ${ }^{2} \&$ Claudio J. B. de Carvalho ${ }^{1}$
}

1Departamento de Zoologia, Universidade Federal do Paraná, Caixa Postal 19020, 81581-580 Curitiba-PR, Brazil. ochoa310@gmail.com;
cjbcarva@ufpr.br
22Laboratorio de Entomologia, IADIZA, CCT-Mendoza (CONICET), Mendoza, Argentina. mcdomin@mendoza-conicet.gov.ar

\begin{abstract}
Revision of the Central American species of Euryomma Stein (Diptera, Fanniidae), with description of two new species and updates of distributional records. Euryomma is the second largest genus within Fanniidae, but only two species, E. panamensis Chillcott, 1958 and E. rettenmeyeri Chillcott, 1958 have been recorded in Central America. In this paper we describe two new species of the genus found in Costa Rica, Euryomma chillcotti sp. nov. (Province of Puntarenas) and Euryomma steini sp. nov. (Provinces of Cartago and Limón). Euryomma tahami Grisales, Wolff \& Carvalho, 2012 is recorded for the first time to Costa Rica. Identification key to all species found in Central America, descriptions and re-descriptions of species occurring in the region and illustrations of the terminalia of new species are presented.
\end{abstract}

KEYWORDS. Biodiversity; Neotropical region; taxonomy.

RESUMO. Revisão das espécies de Euryomma Stein (Diptera, Fanniidae), da América Central, com a descrição de duas espécies novas e a atualização de registros de distribuição. Euryomma é o segundo maior gênero dentro de Fanniidae, mas apenas duas espécies são conhecidas para América Central, E. panamensis Chillcott, 1958 e E. rettenmeyeri Chillcott, 1958. Nesta contribuição são descritas duas espécies novas do gênero encontradas na Costa Rica, Euryomma chillcotti sp. nov. (Província de Puntarenas) e Euryomma steini sp. nov. (Províncias de Cartago e Limón). Euryomma tahami Grisales, Wolff \& Carvalho, 2012 é registrada pela primeira vez na Costa Rica. É apresentada uma chave de identificação para as espécies da América Central, descrições e redescrições das espécies que ocorrem na região, assim como ilustrações da terminália das espécies novas.

PALAVRAS-CHAVE: Biodiversidade; Região Neotropical; taxonomia.

Euryomma Stein, 1899 is the second largest genus within the family Fanniidae; and comprises 17 species in the Neotropical region and two species in the Nearctic region $(E$. peregrinum (Meigen, 1826) and E. americanum Chillcott, 1961), (Chillcott 1961; de Carvalho et al. 2003; Wendt \& de Carvalho 2007; Grisales et al. 2012). Only two species have been recorded in Central America: E. panamensis Chillcott, 1958 and E. rettenmeyeri Chillcott, 1958. Both are known only from the Barro Colorado Island in the Panama Canal Zone.

The species of Euryomma are associated with synanthropic or forest environments, and different types of decomposing matter of vegetable or animal origin (Chillcott 1958; Grisales et al. 2012). The two previously known Central American species were found in association with colonies of army ants, Eciton burchelli (Westwood, 1842). Adults were collected flying above ant's refuse heaps, while the larvae were taken in Berlesse samples of the refuse deposits (Chillcott 1958). Different species of Euryomma can be collected with traps baited with fish, viscera or dung, and some species are important in forensic studies because they visit pig and guinea pig carcasses (de Carvalho \& Pamplona 1979; de Carvalho et al. 2002; Grisales et al. 2012).
In the present paper we revise the species of Euryomma of Central America, describe two new species and update the distributional data of the genus in the region.

\section{MATERIAL AND METHODS}

This study is based on the examination of specimens borrowed from the following institutions (abbreviations used in text): CEUA, Colección Entomológica Universidad de Antioquia, Medellín, Colombia; CNC, Canadian National Collection of insects, arachnids and nematodes, Ottawa, Canada; DZUP, Coleção Entomológica Pe. Jesus Santiago Moure, Universidade Federal do Paraná, Curitiba, Brazil; INBio, Instituto Nacional de Biodiversidad, Santo Domingo de Heredia, Costa Rica.

Species identifications were conducted with the help of taxonomic keys by de Carvalho \& Pamplona (1979), Wendt \& de Carvalho (2007) and Grisales et al. (2012). Comparisons with original species descriptions by Stein (1911), Séguy (1941), Albuquerque (1956), Chillcott (1958), de Carvalho \& Pamplona (1979) and Grisales et al. (2012) were conducted.

We used the terminology proposed by McAlpine (1981) and Stuckenberg (1999) in the species diagnosis and descrip- 
tions. The following abbreviations were used in the descriptions (Grisales et al. 2012): Head. Fr: frontal setae; orb: fronto-orbital setae; oc: ocellar setae; poc: post-ocellar setae. Thorax. Acr: acrostichal setae; $d c$ : dorsocentral setae; ia: intra-alar setae; kepst: katepisternal setae; prepm: proepimeral setae; pprn: postpronotum; pra: pre-alar setae; spal: supra-alar setae. Legs. $A$ : anterior seta; $a d$ : anterodorsal seta; $a v$ : anteroventral seta; $d$ : dorsal seta; $p d$ : posterodorsal seta; $p$ : posterior seta; $p v$ : posteroventral seta; $v$ : ventral seta.

The length of the body was measured from the frons to the apex of the abdomen. The wing was measured from the alar sclerites to the apex of the wing. The interocular space was measured at the narrowest portion of the frontal area.

In order to study the terminalia, we placed the abdomen of each specimen in potassium hydroxide $(\mathrm{KOH}) 10 \%$ at room temperature for 1-2 days. We then dissected the genital parts in glycerin and illustrated them under an optical microscope with a camera lucida. All dissected structures were stored in plastic microvials containing glycerin and pinned with the respective specimen.

Label data of all examined specimens are quoted verbatim as they appear on the label with a slash $(\backslash)$ denoting the end of a line and the end of a label is indicated with a semicolon (;). Clarifying comments are included within brackets and "Idem" is used for specimens listed from the same locality. Species distributions were based on examined material and reliable published records.

\section{TAXONOMY}

\section{Euryomma Stein}

Euryomma Stein, 1899: 19. Type-species: Euryomma hispaniense Stein, 1899 = Euryomma peregrinum (Meigen, 1826).

Diagnosis: Head of male and female without sexual dimorphism, dichoptic in both; male with two pairs of orb; thorax with first presutural $d c$ less than half or half the length of second presutural seta; two strong katepisternal setae and median, weak seta; wing with vein $\mathrm{A}_{2}$ slightly curved and imaginary extension of anal veins meeting near wing margin; abdomen wider before posterior margin of second tergite; male with cercal plate formed by cerci fused on different parts (basally, median area or apically); male without bacilliform process; aedeagus sclerotized and elongated; female with two spherical spermathecae; larval integument reticulated and bearing spicules (Chillcott 1961; Roskosny et al. 1997).

Distribution: Most species of Euryomma are found in the Neotropical region, and two species occur in the Nearctic Region (Chillcott 1961). One species, E. peregrinum (Meigen, 1826), is cosmopolitan (Pont 1977, 1989).

Remarks: The external morphological characters within Euryomma tend to be very homogenous; contrasting with the genus Fannia, the species of Euryomma lack sexual dimorphism and therefore secondary sexual characters are mostly absent. This has led us to use external morphological characters combined with characters of the male terminalia to separate among the species of Euryomma (de Carvalho \& Pamplona. 1979; Wendt \& de Carvalho 2007; Grisales et al. 2012). However, Euryomma steini Grisales \& Carvalho, sp. nov. presents two external morphological characters (one pair of fronto-orbital setae, the remaining species of the genus have two pairs and abdomen with syntergite $1+2$ and tergite 3 yellow translucent) that distinguish it from most other species of the genus and suggest that it could be morphologically related to E. palpingens Wendt \& Carvalho, 2007 (Wendt \& de Carvalho 2007).

Despite the fact that Central America is one of the most biodiverse places in the world, little is known about the Central American species of Euryomma. The same can be extended to the Neotropical region as a whole. Since Chillcott's first study (1958), additional information on the Central American Euryomma, which is summarized in this paper, has been acquired. In this contribution, the number of species known to Central America is increased to five, and the number of known species in the Neotropical region increases to 19.

\section{Key to the males of Euryomma of Central America}

1. Scutum with five longitudinal vittae following $a c r$ and $d c$ setae, and the intra-alar area ........................................ 2

1 '. Scutum with three longitudinal vittae following $a c r$ and $d c$ setae ... 3

2. Antennae with arista short pubescent (hairs shorter than width of base of arista), scape brown with apical margin yellowish, pedicel brown and yellowish around suture; (Figs. 1-4) ........Euryomma chillcotti Grisales \& Carvalho, sp. nov.

2' Antenna with arista long pubescent (hairs four times the width of base of arista), scape yellow tinged with fuscous and pedicel yellow ...... Euryomma panamensis Chillcott

3. Head, one pair of $o r b$, anterior one absent; abdomen with sintergite $1+2$ and tergite 3 yellow translucent

............. Euryomma steini Grisales \& Carvalho, sp. nov.

3'. Head, two pairs of orb, anterior and posterior presents; abdomen without above pattern

4

4. Hind tibia without anteroventral bristle; palpus basally yellowish (yellow color extending along dorsal margin to apical fourth), otherwise dark .. Euryomma rettenmeyeri Chillcott

4'. Hind tibia with anteroventral bristle; palpus completely brown .... Euryomma tahami Grisales, Wolff \& Carvalho

\section{Euryomma chillcotti Grisales \& Carvalho, sp. nov.}

(Figs. 1-4)

Diagnosis: Scutum with five vittae along $a c r$ and $d c$, and ia area; antenna with arista short-pubescent (hairs shorter than width of base of arista), scape brown with apical margin yellowish, pedicel brown and yellowish around suture; hind tibia yellow with brownish ring on basal third; abdomen with sternite 5 with two sclerotized, curved, concave 
and elongated plates, plates with strong setae on apical area, and joined by another plate covered with strong spines.

Description: Male holotype: Body length $4 \mathrm{~mm}$; wing length $3.5 \mathrm{~mm}$.

Head: Eye with sparse setulae. Frontal vitta brownish with anterior margin slightly reddish, covered with golden yellow pollinosity. Interocular space $0.5 \mathrm{~mm}$. Two pairs of $f r$, with weak intercalated setae. Two pairs of $o r b$, anterior pair lateroclinate, posterior pair reclinate. Ocellar tubercle with golden yellow pollinosity; one pair of $o c$, proclinate and strong, posterior area surrounded by a few setulae. Poc divergent. Fronto-orbital plate, parafacial and gena with golden yellow pollinosity. Parafacialia with short setae on dorsal half. Scape brown with anterior margin yellowish, pollinose and with a seta reaching pedicel. Pedicel brown, yellowish around suture. Postpedicel dark brown with golden yellow pollinosity, three times the length of pedicel. Arista brown except for yellowish basal third, bearing short pubescence, hairs shorter than width of base of arista. Palpus dark brown, flat and claviform.

Thorax: light grey with golden yellow pollinosity, scutum with five brown vittae along $a c r, d c$ and $i a$, median vitta expanded from base to apex of scutellum, $d c$ vitta expanded up to scutellar basal area. Acr 3:3-4, in irregular rows. Dc 2:3. Pprn with two well-developed and a weaker third setae, postpronotal area with setulae. Two pra, both well developed. Two prepm, seta closest to spiracle longer, proepimeral area bare. Kepst 1:1, one weak seta in between, without setulae in the katepisternal area.

Wing: faintly brownish, with apical third, between $\mathrm{C}$ vein and apical half of vein $\mathrm{R}_{2+3}$ faintly darkened. Calypters and halter yellowish.

Legs: coxae and femora dark brown; trochanter, apex of femur, fore and mid tibiae yellow; hind tibia yellow with brownish ring on basal third; tarsi brown; pulvilli brownish. Fore femur with a row of short $a v$; one series of long and strong $d$; one row of $p d$; posterior surface setulose, with thin $p$; one series of long $p v$ on apical half; ventral surface bare. Fore tibia with one long pre-apical $d$; one sub-median and one pre-apical $a d$; one apical $p v$ and one apical $v$. Basal tarsomere of fore leg with one strong and short basal $v$. Mid femur weakly constricted on ventral pre-apical surface; one row of short $a v$, setae closer-set and with hooked apex on apical half; one row of short $a d$ towards $a$ surface, pre-apex with two short $a d$; four strong pre-apical $p$; one strong basal $p v$ and one row of short, hooked $p v$; one row of short hooked $v$, near row of $p v$. Mid tibia setulose on ventral surface, with two pre-apical $v$, one short and one long; one apical $a$; one long apical $a v$; one submedian $a d$; posterodorsal surface bare; one median and one apical $p$; one short apical $p v$. Hind coxa with one setula on posterior margin. Hind femur with one row of $a d$ on apical half; two strong pre-apical $a v$; ventral surface bare; one preapical $d$; one short pre-apical $p d$; posteroventral and posterior surfaces without differentiated setae. Hind tibia with one strong median $d$; one median and one pre-apical $a d$; one median and one apical strong $a v$; one strong apical $p v$. First tarsomere of hind tarsus strongly setulose on basal ventral surface.
Abdomen: light grey and dark brown, golden yellow pollinose. All tergites light grey on basal third. Sternite 1 bare. Sternite 5 (Fig. 1): with two sclerotized, curved, concave and elongated plates, plates with strong setae on apical area, and joined by another plate covered with strong spines. Terminalia (Figs. 2, 3): epandrium broader than long, covered with weak setae, with short acute projections on latero-apical portion; surstylus wide, three times longer than latero-apical epandrial projections, articulated with epandrium and bearing short setae; cercal plate enlarged and concave, rounded and strongly setulose on median area. Hypandrium and associated structures as in Fig. 4.
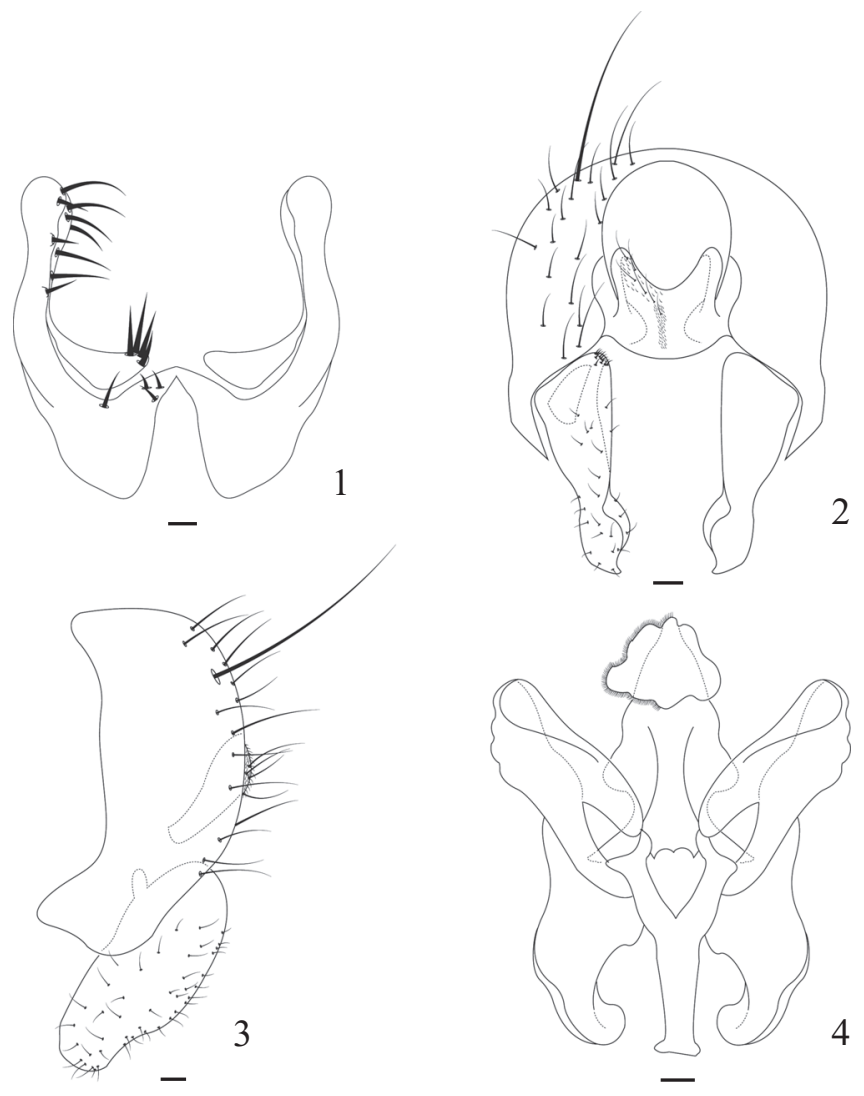

Figs. 1-4. Euryomma chillcotti sp. nov., male terminalia: 1, sternite 5, ventral view; 2, epandrium, dorsal plate and surstylus, dorsal view; 3, epandrium, dorsal plate and surstylus, lateral view; 4, hypandrium and associated structures, dorsal view. Scale bars: $0.1 \mathrm{~mm}$.

Female: unknown.

Comments: Euryomma chillcotti Grisales \& Carvalho, sp. nov. and Euryomma uwa Grisales, Wolff \& Carvalho, 2012, are similar. They differ mainly in characters of the male terminalia: in E. chillcotti the epandrium is broader than in E. uwa, the cercal plate is broader, and the basal area is rounded (Figs. 2, 3). The male terminalia is very distinctive and sufficient to separate E. chillcotti from previously described species. The holotype is in perfect condition.

Etymology: The specific epithet, chillcotti, is in homage to J. G. Chillcott for his extensive contribution to the knowledge of Fanniidae.

Revista Brasileira de Entomologia 56(4): 451-457, dezembro, 2012 
Type-material: (male holotype, INBio): San Luis, Monteverde, Prov. Punta [Puntarenas] $\backslash$ COSTA RICA. 1040 m. nov 1993, Z. $\backslash$ Fuentes, L N 250850_449250 \#2443. INBIO CRI001938318.

Paratypes: P.N. Tapantí, A.C. Amistad, Prov. Carta [Cartago], COSTA RICA. 1150 m. Ene 1994, G. Mora, \L N 194000_559800 \# 2578. INBIO CRI001 830726 (2 males, INBio); Costa Rica. Prov. Puntarenas, P.N. $\backslash$ La Amistad, Coto Brus, Estación \Pittier, Fila Pittier. 2200 m, 19 FEB $\backslash 2002$. M. Alfaro, Red de Golpe. \L_S_332800_579050 \# 66967. INB0003432767 INBIOCRI COSTA RICA (1 male, INBio).

Distribution: Costa Rica, Provinces of Puntarenas and Cartago.

\section{Euryomma panamensis Chillcott}

Euryomma panamensis Chillcott, 1958: 730, figs. 4-6, 8, 17-20. Holotype male, SEMC, paratypes, BMNH, CNC. Type-locality: Panama Canal Zone, Barro Colorado Is. Dist.-Panama.

Diagnosis: Basal antennal segments yellowish and white, arista long pubescent and palpus dark grey; abdomen with sternite 5 completely divided in medial area, each half produced into slender process in outer margin, this process bears two apical and a pre-apical setae, posterior margin with 2 to 3 setae and several setulae, anterior margin membranous with few short setulae.

Redescription: Male holotype: body length $3 \mathrm{~mm}$; wing length $2.7 \mathrm{~mm}$.

Head: Eye bare. Frontal vitta brownish, reddish on anterior margin. Interocular space $0.4 \mathrm{~mm}$. Two pairs of $f r$, with two intercalated setulae. Two pairs of $o r b$, both reclinate. Ocellar triangle silvery pollinose; with one pair of proclinate and strong $o c$, posterior area of ocellar triangle with few setulae. Poc divergent. Fronto-orbital plate, parafacial and gena grey pollinose. Parafacial with four short setulae on dorsal fourth. Scape brown with yellow anterior margin; pedicel brown at base, yellowish at apex and around suture; postpedicel three times the length of pedicel, dark brown with heavy grey pollinosity; arista light brown, bearing long pubescence, hairs 1.5 times the width of base of arista. Palpus dark brown, straight, the apex as wide as the base.

Thorax: grey brown pollinose, scutum with five brown vittae along $a c, d c$, and $i a$, median vitta narrow, extending to base of scutellum; $d c$ vitta thin and interrupted, extending to apex of scutellum, and $i a$ vitta diffuse and broader than former. Acr 3:3 in irregular rows; dc 2:3-3. Pprn with two strong and a weaker setae, postpronotal area with few setulae. Two pra, anterior one longer, near the suture, and one weaker above the first spal. Two prepm, the closest to spiracle longer; proepimeral area bare. Kepst, with no distinct medial setulae, katepisternum with short setulae.

Wing: clear, calypters and halter pale yellow.

Legs: dark brown, except for femoral apex and tibial bases. Pulvilli white. Fore femur with a row of five $p d$; dorsal surface covered with setulae; one row of $p v$ formed by weak and short setulae basally and three strong setae at apex. Fore tibia with one strong pre-apical $d$; one very weak submedial $a d$; one apical $v$; one apical $p v$. Basal fore tarsomere with short and strong setae on ventral surface. Mid femur with one row of $a v$, less than half as long as femoral diameter, weak, becoming shorter and closer-set apically to form a weak comb; one row of $p v$, stronger at the apex, weakly duplicated ventrally on media third; one row of $a d$, short, longer and directed to anterior surface; four pre-apical $p$. Mid tibia only weakly thicker apically; ventral pubescence short and multiserial; one apical $p v$; one long and strong apical $v$; one apical $a v$; one submedian and one strong and long apical $a$; one long and strong apical $a d$; one submedian and one apical $p$. Hind coxa with one setulae on posterior margin. Hind femur with one row of long $a d$, directed to dorsal surface at apex; one row of $a v$, setulose except for two setae at apex; posteroventral surface setulose. Hind tibia with one submedian; one apical $a v$; one submedian and one preapical $a d$; two long $d$. Ventral surface on hind tarsomere I strongly setulose.

Abdomen: dark brownish and grey pollinose, laterally with pale grey anterior margins, grey pollinose expanded laterally to cover anterior half margin of each segment. Hypopygium weakly projecting. Sternite 5, completely divided in medial area, each half produced into slender process in outer margin, this process bears two apical and a pre-apical setae. Posterior margin with 2 to 3 setae and several setulae; anterior margin membranous with few short setulae. Terminalia (see Chillcott 1958, Figs. 4-5): epandrium as long as broad, bell-shaped, with one strong and several weaker setae; surstylus partially fused to epandrium, narrow at base then rapidly broadening to form a triangle; cercal plate short and broad. Hypandrium slender, interrupted medially, with a long basal flange directed inwardly.

Female: Not examined.

Comments: This species can be separated from all other species of Euryomma, except E. nigrifemur Stein, 1911, E. palpingens Wendt \& Carvalho, 2007, E. rettenmeyeri Chillcott, 1958 and $E$. steini $\mathbf{s p . ~ n o v . ~ b y ~ t h e ~ d a r k ~ b r o w n ~ f e m o r a ~ a n d ~ b r o w n ~}$ tibia. See diagnosis of $E$. panamensis for specific characters.

Type-material examined: (1 male, paratype, CNC): Barro Colorado I Canal Zone, Panama $\backslash 28-$ III-1956 No.580 $\backslash$ C.W. \& M. E. Rettenmeyer; Eciton burchelli $\backslash$ refuse deposit $\backslash$ Nomadic Day; PARATYPE $\backslash$ Euryomma $\mathrm{M} \backslash$ panamensis/ No. Chillcott.

Distribution: Panama, Canal Zone, Barro Colorado Is.

\section{Euryomma rettenmeyeri Chillcott}

\section{Euryomma rettenmeyeri Chillcott 1958: 725, figs. 1-3, 7, 9-16, 21. Holo- type male SEMC, paratypes, BMNH, CNC. Type-locality: Panama Canal Zone, Barro Colorado Is}

Diagnosis: Clear yellow basal antennal segments, basally yellowish palpus and, in the male, absence of a hind tibial anteroventral seta; abdomen with sternite 5 transversally divided by a membranous band, except at lateral margin, these are produced into short and thick processes, bearing 4-5 apical and pre-apical setae; anterior margin sclerotized bearing several weak setae, median line with three strong and several weak setae. 
Redescription: Male: body length $3.4 \mathrm{~mm}$; wing length $2.6 \mathrm{~mm}$.

Head: Eye bare. Frontal vitta dark brown, dark reddish on anterior margin. Interocular space $0.4 \mathrm{~mm}$. Two pairs of $f r$, with two intercalated setulae. Two pairs of orb, both reclinate. Ocellar triangle grey silvery pollinose; with one pair of proclinate and strong $o c$, posterior area of ocellar triangle with few setulae. Poc divergent. Fronto-orbital plate, parafacial and gena grey pollinose. Parafacial with four short setulae on dorsal fourth. Scape and pedicel yellow; postpedicel dark grey with heavy grey pollinosity, three times the length of pedicel; arista yellow in basal $1 / 5$, dark grey apically, bearing long pubescence, hairs 1,5 times width of base of arista. Palpus basally yellow, the yellow extending along dorsal margin to apical fourth, remaining dark, straight, the apex as wide as base.

Thorax: Pale yellowish brown. Scutum with three brown vittae along $a c$ and spal; scutellum pale yellowish brown with two sub-basal dark brown spots. Acr 3: 3-4 in irregular rows; dc 2: 3-3; pprn, two strong and one weaker, postpronotal area with few setulae; two pra, anterior one longer, near the suture, and one weaker above the first spal; two prepm, the closest to spiracle longer, proepimeral area bare; two kepst, with no distinct medial setulae, katepisternum with short setulae.

Wing: clear, calypter and halter pale yellowish-white.

Legs: dark brown, except for femoral apices and tibial bases. Pulvilli white. Fore femur with one row of strong $p d$, as long as femoral width; dorsal surface covered with setulae; one row of $p v$ formed by weak and short setulae basally and two strong setae at apex; anterior surface covered with short setulae. Fore tibia with one strong subapical $d$; one submedial $a d$; one apical $v$; one apical $p v$. Basal fore tarsomere with short and strong setae on ventral surface. Mid femur with one row of short $a v$, less than half as long as femoral width, weak, becoming shorter and closer-set apically to form a weak comb; one row of short $p v$, less than half as long as femoral width, weak, becoming shorter and closer-set apically to form a weak comb; one row of $a d$, only present in median half, and one pre-apical setae separated from row. Mid tibia only slightly thicker apically; ventral pubescence short and multiserial; one apical $p v$; one long and strong apical $v$; one apical $a v$; one submedian and one strong and long apical $a$; one long and strong apical $a d$; one submedian and one apical $p$. Hind coxa with one setulae on posterior margin. Hind femur with one row of long $a d$, toward to dorsal surface at apex; one row of $a v$, setulose except for two setae at apex; posteroventral surface setulose. Hind tibia lacking $a v$; one submedian and one preapical $a d$; two long $d$. Ventral surface on hind basal tarsomere strongly setulose.

Abdomen: Dark brownish, grey pollinose, laterally with pale grey anterior margins, grey pollinose expanded lateral to cover anterior half margin of each segment. Hypopygium weakly projecting. Sternite 5 transversally divided by a membranous band, except at lateral margin, these are produced into short and thick processes, bearing $4-5$ apical and pre- apical setae; anterior margin sclerotized bearing several weak setae, median line with three strong and several weak setae. Terminalia (see Chillcott 1958, Figs. 1-3): epandrium shorter than broad, rounded, with one strong and several weaker setae; surstylus not fused to epandrium, basally broad with a rounded dorsal expansion medially, ventral and mid dorsal margins bearing several bristle like hairs; cercal plate elongate and slender; hypandrium broad, interrupted medially, basal flange broad, directed outwards.

Female: body length $2.9 \mathrm{~mm}$; wing length $2.5 \mathrm{~mm}$. Differs from male as follows:

Legs: rows of $a v$ and $p v$ of mid femur setulose at apex, basally with 5-6 short setae on each surface; hind tibia with one strong $a v ; d$ shorter $(0.5$ and $0.7 \mathrm{~mm})$.

Abdomen: Similar color to the male, except for dorsocentral vitta, which is less apparent. Terminalia not examined (see Chillcott 1958, Fig. 7).

Comments: This species is distinguished from all other species of Euryomma by the absence of hind tibial anteroventral setae (see diagnosis).

Type-material examined: (1 male, paratype, CNC): Barro Colorado I/ Canal zone, Panama/ 23-V-1956 No. 1841/ C. W. \& M. F. Rettenmeyer; Eciton burchelli/ Refuse deposit/ Colony E-156/ Statary Day N-2; Reared from refuse/ Deposit of Eciton/ burchelli/ emerged 10-VI; PARATYPE/ Euryomma M/rettenmeyeri/ No. Chillcott; (1 female, Paratype, CNC): Barro Colorado I/ Canal zone, Panama/ 23-V-1956 No. 1841/ C. W. \& M. F. Rettenmeyer; Eciton burchelli/ Refuse deposit/ Colony E-156/ Statary Day N-2; emerged 10-VI-56; PARATYPE/ Euryomma F/ rettenmeyeri/ No Chillcott.

Other material examined: PANAMA. Barro Colorado Is.: (1 male, 1 female, CNC) Panama Canal Zone, C.Z, 9/III/1955 No. 991, Carl W. Rettenmeyer; $1 \mathrm{~m}$. radius of bivouac; Eciton burchelli Bivouac site, Colony B-IV-S Euryomma M rettenmeyeri, Chillcott Det. 1958, J. G. Chillcott.

Distribution: Panama, Canal Zone, Barro Colorado Is.

\section{Euryomma steini Grisales \& Carvalho, sp. nov.}

(Figs. 10-8)

Diagnosis: Head with one pair of $o r b$. Scape brown with anterior margin slightly reddish, pedicel brown, slightly reddish around suture; arista brown, bearing long hairs, basal third brownish; palpus dark brown, flat and claviform, four times the width of base of palpus. Abdomen with sintergite $1+2$ and tergite 3 yellow translucent, sternite 5 one plate with strong setae on apical half.

Description: Male holotype: body length $2.5 \mathrm{~mm}$; wing length $2.4 \mathrm{~mm}$.

Head: eyes bare. Frontal vitta brownish with anterior margin reddish. Interocular space $0.32 \mathrm{~mm}$. Two pairs of $f r$, with intercalated weak setae. One pair of reclinate $o r b$. Ocellar tubercle with one pair of proclinate $o c$, posterior area surrounded by few setulae. Poc parallel. Fronto-orbital plate, parafacial and gena with silver pollinosity. Parafacial with short setae on dorsal half. Scape brown with anterior margin slightly reddish, with two setae reaching pedicel. Pedicel brown, slightly reddish around suture. Postpedicel dark brown 
with golden yellow pollinosity, three times the length of pedicel. Arista brown with basal third brownish, bearing long hairs, hairs as width of base of arista. Palpus dark brown, flat and claviform.

Thorax: brownish with golden yellow pollinosity, scutum with three brown vittae along $a c r$ and $d c$. Acr 3:3-2, in regular rows; $d c$ 2:3; pprn with two strong setae, and a third weaker, postpronotal area with setulae; two pra; one strong and one weak prepm, proepimeral area without setulae; kepst $1: 1$, with one weakly developed seta between them, katepisternal area with short setulae.

Wing: yellowish. Calypters yellowish. Halter yellow.

Legs: brownish with tarsi dark brown; pulvilli yellowish. Fore femur with one row of short $a v$; one series of long and strong $d$; one row of $p d$; posterior surface setulose, with thin setae; one series of long $p v$ on apical half. Fore tibia with one pre-apical $d$; one apical $p v$ and one longer (than $p v$ ) apical $v$. Basal tarsomere of fore leg with strong basal $v$. Mid femur with one row of short $a v$, setae closer-set and hooked at apex on apical half; one row of $a d$ on basal half, pre-apex with two short setae; three pre-apical strong $p$; one row of $p v$ and $v$, both short, hooked; row of $v$ near to $p v$. Mid tibia ventrally setulose, with two pre-apical $v$, one short and one long; one apical seta and one sub-median $a$; one apical $a v$; one short apical $p v$. Hind coxa with one setula on posterior margin. Hind femur with two ad on apical half; two strong preapical $a v$; two pre-apical $d . P v$ and $p$ surface without differentiated seta. Hind tibia with one sub-median seta and one pre-apical $d$; one median, one pre-apical seta and one apical $a$; one median and one strong apical $a v$; one strong apical $p v$; one sub-median $p d$. Hind first tarsomere strongly setulose on ventral surface.

Abdomen: light grey with sintergite $1+2$ and tergite 3 yellow translucent. Sternite 1 bare. Sternite 5 (Fig. 5): one plate with strong setae on apical half. Terminalia (Figs. 6, 7): epandrium wide, covered with weakly developed setae on basal half; surstylus wide with short setae, fused with epandrium, elongated and acute on apex; cercal plate (formed by the fusion of the cerci) concave, slightly rounded on apex, with long and curly setae. Hypandrium and associated structures as in Fig. 8.

Female: unknown.

Comments: Euryomma steini Grisales \& Carvalho, sp. nov. and Euryomma palpingens Wendt \& Carvalho, 2007 are similar; they share the following characters, which could indicate morphological proximity: the absence of the inferior orb bristle in the male; the abdomen with sintergite $1+2$ and tergite 3 yellow translucent and surstylus elongated and fused with epandrium. The palpus of E. steini, however, is not as well developed as that of $E$. palpingens. These species differ mainly in characters of the male terminalia such as the shape of sternite 5, shape of surstylus and cercal plate (Figs. $7,8)$. The holotype lacks the abdomen because the terminalia was dissected.

Etymology: The specific epithet, steini, is in homage to P. Stein for his contribution to the knowledge of Diptera.

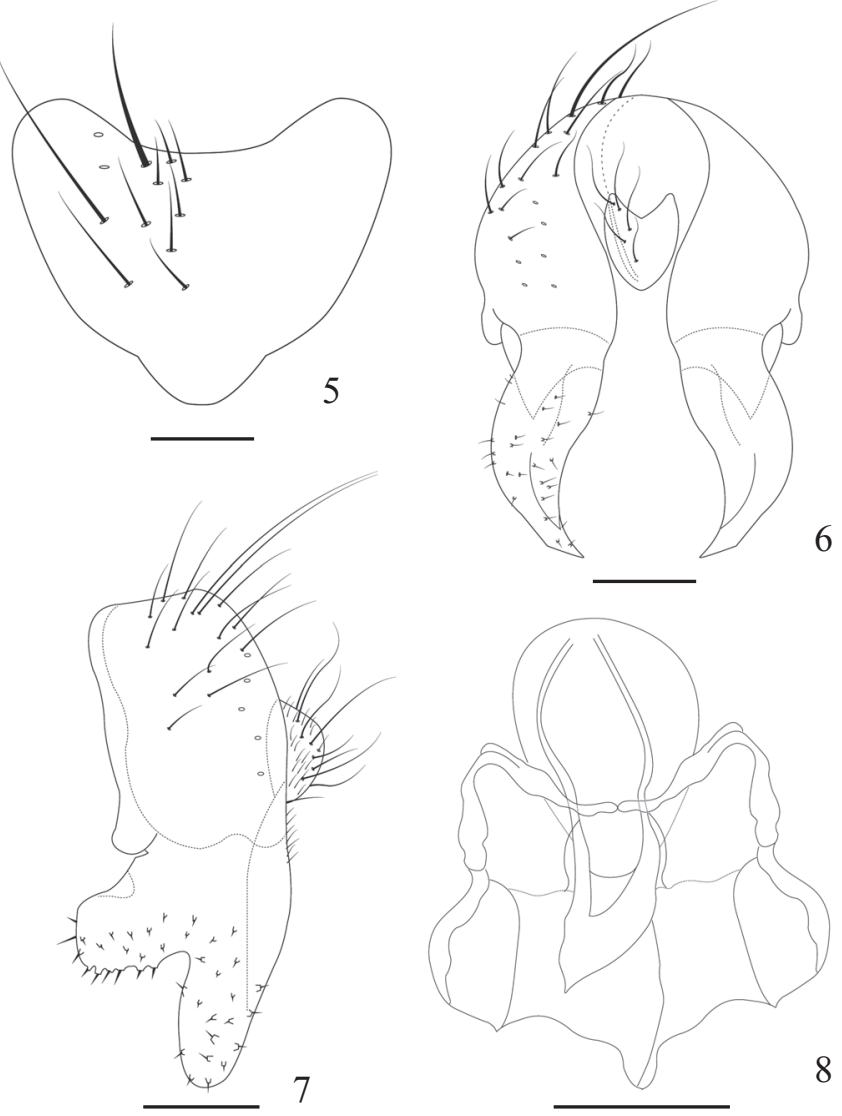

Figs. 5-8. Euryomma steini $\mathbf{s p . ~ n o v . , ~ m a l e ~ t e r m i n a l i a : ~ 5 , ~ s t e r n i t e ~ 5 , ~ v e n t r a l ~}$ view; 6, epandrium, dorsal plate and surstylus, dorsal view; 7, epandrium, dorsal plate and surstylus, lateral view; 8 , hypandrium and associated structures, dorsal view. E. steini $\mathbf{s p}$. nov. Scale bars: $0.1 \mathrm{~mm}$.

Type-material: (male holotype, INBio): COSTA RICA. Prov. Limón. R.B. Hitoy Cerere. Send. Espavel. 560m. 17 \MAR 2003. B. Gamboa. Libre.। L S 401200569800 \#73281; INB0003703748 INBIOCRI COSTA RICA.

Distribution: Costa Rica, Province of Limón.

\section{Euryomma tahami Grisales, Wolff \& Carvalho}

Euryomma tahami Grisales, Wolff \& Carvalho, 2012: 803-829, figs. 1-5. Holotype male, CEUA, paratypes, CEUA. Type-locality: Colombia, Antioquia, Medellin.

Diagnosis: Frontal vitta brown with anterior margin yellowish; length of postpedicel 3.6 times the length of pedicel; scutum with three well-defined vittae, median vitta conspicuous; male terminalia with cercal plate narrow, strongly concave and pointed apically; abdomen with sternite 5 with two concave and elongated plates, basal portion

setulose and with strong setae; plates joined by a membrane covered with short setae.

Comments: Euryomma tahami was recorded to the Central Cordillera in Colombia, from $770 \mathrm{~m}$ to $1,450 \mathrm{~m}$ high, and in association with decomposing organic matter (Grisales et al. 2012). The present paper is the first record of this species in Costa Rica. 
Female: Unknown.

Type-material examined: (1 male, holotype, CEUA): Colombia. Antioquia. Medellín\Universidad de Antioquia. Ciudad Universitaria. 1450 m. Pitfall copro\Agosto 27/2002 \Díaz y Monsalve CEUA; ( 6 males, paratypes, CEUA): Colombia. Antioquia. Medellín\Universidad de Antioquia. Ciudad Universitaria. $1450 \mathrm{~m}$. Pitfall copro\Agosto 27/2002 \íaz e Monsalve CEUA; (1 male, paratype, CEUA): CO [Colombia]. Ant. [Antioquia]. La Pintada. Hda. [Hacienda] Montenegro $\backslash$ Comfenalco. 850 m. Bosque. 543’24"N; 75³7'15"W. H 18:00\VSR [Van Someren-Rydon trap] pescado. Febrero 16/2007\N. Uribe. CEUA; (1 male, paratype, CEUA): CO [Colombia]. Ant. [Antioquia]. La Pintada. Hda. [Hacienda] Montenegro $\backslash$ Comfenalco. $770 \mathrm{~m}$. Potrero. VSR Ivísceras. 543'25"N; 75³7’15"WIVSR [Van Someren-Rydon trap]. Abril 19/2007. Vísceras. L.A. Vergara. CEUA.

Other material examined: COSTA RICA: Província Puntarenas: (1 male, INBio) Fca. Cafrosa, Est. Las Mellizas, P. N. Amistad, 1300m, G. Mora. Abr 1991, L-S-316100, 596100.

Distribution: Colombia, Department of Antioquia; Costa Rica, Province of Puntarenas.

\section{ACKNOWLEDGMENTS}

We are thankful to Manuel Zumbado (INBio) and James O'Hara (CNC) for access to specimens. We also thank to Rosana M. da Rocha and anonymous referees for comments and suggestions on this manuscript. Financial support was provided by a CAPES/CNPq-IEL Nacional (Brazil) doctoral grant to D. G. CJBC is a CNPq fellow (process \# 3047/20112). Finally, M. C. D thanks CONICET (Argentina) for financial support. Contribution number 1835 from the Department of Zoology, Universidade Federal do Paraná.

\section{REFERENCES}

Albuquerque, D de O. 1956. Fauna do Distrito Federal. XXXI. Contribuição ao conhecimento de Euryomma Stein, 1899, com descrição de uma espécie nova (Diptera-Muscidae). Boletim do Museu Nacional Rio de Janeiro (Zoologia) 136: 1-6.
Chillcott, J. G. 1958. Two new species of Euryomma (Stein) (Muscidae: Diptera) from Panama. Canadian Entomologist 90: 725-731.

Chillcott, J. G. 1961. A Revision of the Neartic Species of Fanniinae (Diptera: Muscidae). Canadian Entomologist 92: 1-295.

de Carvalho, C. J. B. \& D. Pamplona. 1979. Sobre uma nova espécie de Euryomma Stein, 1899 (Diptera, Fanniidae). Revista Brasileira de Biologia 39: 601-604.

de Carvalho, C. J. B.; M. O. Moura \& P. B. Ribeiro. 2002. Chave para adultos de dípteros (Muscidae, Fanniidae, Anthomyiidae) associados ao ambiente humano no Brasil. Revista Brasileira de Entomologia 46: 107-114.

de Carvalho, C. J. B.; A. C. Pont; M. S. Couri \& D. Pamplona. 2003. A catalogue of the Fanniidae (Diptera) of the Neotropical Region. Zootaxa 219: $1-32$

Grisales, D.; M. Wolff \& C. J. B. de Carvalho. 2012. Neotropical Fanniidae (Insecta: Diptera): new species of Euryomma Stein from Colombia. Journal of Natural History 46: 803-829.

McAlpine, J. F. 1981. Morphology and terminology - adults, p. 9-63. In: J. F. McAlpine; B. V. Peterson; G. E. Shewell; H. J. Teskey; J. R. Vockeroth $\&$ D. M. Wood (Eds.). Manual of Nearctic Diptera. Vol. 1. Agriculture Canada Monograph 27, vi+674 p.

Pont, A. C. 1977. A revision of Australian Fanniidae (Diptera: Calyptrata). Australian Journal of Zoology, Supplementary Series 51: 1-60.

Pont, A. C. 1989. Family Fanniidae, p. 700-701. In: N. L. Evenhuis (ed.). Catalog of the Diptera of Australasian and Oceanian regions. Bishop Museum Special publication. Bishop Museum Press \& E. J. Brill Honolulu, 804 p.

Roskosny, R.; F. Gregor \& A. C. Pont. 1997. The European Fanniidae (Diptera). Acta Scientiarum Naturalium Academiae Scientiarum Bohemicae-Brno 31: 1-80.

Séguy, E. 1941. Une nouvelle espèce d'Euryomma Stein (Dipt. Muscidae) et synopsis des espèces du genre. Bulletin de la Société Entomologique de France 46: 54-55.

Stein, P. 1899. Euryomma, eine neue Gattung der Anthomyidengruppe Homalomyia. Entomologisches Nachrichtenblatt 25: 19-22.

Stein, P. 1911. Die von Schnuse in Südamerika gefangenen Anthomyiden. Archiv für Naturgeschichte 77: 61-189.

Stuckenberg, B. R. 1999. Antennal evolution in the Brachycera (Diptera), with a reassessment of terminology to the flagellum. Studia dipterologica 6: 33-48.

Wendt, L. D. \& C. J. B. de Carvalho. 2007. Taxonomia de Fanniidae (Diptera) do sul do Brasil - I: nova espécie e chave de identificação de Euryomma Stein. Revista Brasileira de Entomologia 51: 197-204. 